\title{
Back Pain and Body Posture of Non-Professional Brazilian Jiu-Jitsu Athletes
}

\section{Katarzyna Sędek}

Józef Piłsudski University of Physical Education in Warsaw

Aleksandra Truszczyńska-Baszak

Józef Piłsudski University of Physical Education in Warsaw

Anna, Katarzyna Cygańska ( $\nabla$ anna.katarzyna.cyganska@gmail.com )

Józef Piłsudski University of Physical Education in Warsaw

Justyna Drzał-Grabiec

Rzeszów University

\section{Research Article}

Keywords: Brazilian Jiu-Jitsu, martial arts, body posture, back pain

Posted Date: March 6th, 2021

DOI: https://doi.org/10.21203/rs.3.rs-275346/v1

License: (c) (i) This work is licensed under a Creative Commons Attribution 4.0 International License. Read Full License 


\section{Abstract \\ Background}

The aim of the study was to assess the prevalence of back pain in non-professional Brazilian jiu-jitsu (BJJ) athletes, and to assess the relationship between their back pain and postural disorders.

\section{Methods}

The study involved 61 subjects: 31 subjects who trained Brazilian jiu-jitsu and 30 subjects who had never trained any martial arts. The mean BJJ training time in the study population was $3.89 \pm 4.13$ years. The athletes' trained $4.06 \pm 2.8$ times a week and took 1.5 hours. Postural assessments were conducted with the use of the photogrammetric method. The assessment of back pain and injuries was conducted with the Oswestry Disability Index (ODI) and with our proprietary questionnaire.

\section{Results}

Among both populations, 37 subjects reported back pain -22 athletes $(71.0 \%)$ and 15 controls $(50 \%)(p=0,094)$. There were no differences in back pain location between the two groups $(p>0.05)$ or in functional state on the Oswestry Index $(21.5 \%$ in the study population and $20 \%$ in the control group, $p=0.121$ ). We observed significant differences between the groups in the values of four of the postural parameters. For each of these four parameters, parameter values were higher in the study population: DCK-spinal height from C1 to S1 (474.8 \pm 25.4 vs $447.1 \pm 25.9, p=0.001)$; RKP-length of kyphosis between C7 and thoracolumbar junction (321.9 \pm 15.2 vs $307.3 \pm 22.2, \mathrm{p}=0.010)$; RLL-length of lordosis between $\mathrm{S} 1$ and thoracolumbar junction (152.9 \pm 18.2 vs. $139.8 \pm 17.6, p=0.009)$ and KNM-pelvis inclination angle $(2.24 \pm 1.18$ vs. $1.64 \pm 1.34, p=0.041)$. We found statistically significant differences in the study population between the athletes with and without back pain. These differences were found in the following parameters: RKP-length from C7 to peak of kyphosis $(p=0.01)$ and TT-difference between height of the waist triangles $(p=0.018)$.

\section{Conclusions}

There are no differences in back pain in regard to its frequency, intensity and location between non-professional BJJ athletes and subjects who do not train BJJ. Both in the study population and in the control group the spinal pain was minimal or moderate on the Oswestry Disability Index. BJJ athletes who reported back pain had characteristic postural changes in some of the analysed postural parameters in comparison to BJJ athletes who did not report back pain.

\section{Background}

The development of the sports discipline of Brazilian jiu-jitsu (BJJ) and its increasing popularity was followed by an increasing number of publications on the physical and physiological profile of BJJ athletes [1], on the biomechanics aspects of the athletes [2], on the technical and tactical analyses [3, 4], and on the incidence of injuries [5-8]. Brazilian jiu-jitsu (BJJ) is a type of martial art and as such it requires certain physical and physiological qualities, such as mesomorphic somatotype, aerobic and anaerobic power, muscle power and endurance and flexibility [1,2]. Studies on prevalence of injuries in BJJ found that its athletes, similarly to those who do other types of martial arts, suffer from frequent injuries. Depending on the study, as many as $25.5 \%$ [5] to $85.7 \%$ [9] athletes reported having had an injury. The most common were orthopaedic injuries - 78\% [7]. The injuries affect the limbs as well as the torso, and internal organs [9-12]. It has been found that athletes sustain more injuries during training than during competitions [13]. 
Apart from injuries sustained during training and competition, athletes suffer from back pain [14-17], usually in the lumbar spine and a lifetime prevalence reaches up to $94 \%$ [18]. Depending on the test and the time when examinations were conducted (preparation, competition, interim) the point prevalence ranging from 18 to $65 \%$ [18]. The only report available in the literature which discusses the issue of back pain in BBJ athletes is from Reis et al. They found that BJJ athletes of different levels of advancement experience both acute and chronic back pain [19]. Therefore, the natural direction of examination in searching for causes and in assessment of an athlete with back pain is the analysis of their posture. Several authors have analysed posture of athletes of different sports disciplines [20-24]. However, no report on BJJ postural assessment had been found.

Most papers available from the literature on BJJ discuss professional athletes $[5,6]$. In the literature only two papers were available, which focused on the athletes who did BJJ both non-professionally and/ or recreationally $[12,19]$. The population of non-professional BJJ athletes is as big as the population of professional BJJ athletes. Moreover, a professional athlete is supported by qualified training staff, has access to sports base and medical care; while non-professional athletes or persons doing recreational training cannot benefit from that type of support.

The aim of the study was to assess the prevalence of back pain in non-professional Brazilian jiu-jitsu athletes, and to assess the relationship between their back pain and postural disorders.

\section{Methods}

All experimental protocols were approved. authors obtained the consent to conduct the study from the Senate Ethics Committee for Scientific Research (SKE 01-45/2016) and confirmed conducting research to the standards set by the Declaration of Helsinki [25]. The study involved 61 subjects. The study population consisted of 31 Brazilian jiu-jitsu athletes, recruited from sports clubs. The control group were 30 subjects who had never done martial arts. The participants constituted a convenience sample. Each participant was informed about the purpose and procedure of the research, as well as the of possibility of withdrawing at any time during the study. All participants gave their informed consent to participate in the project.

The criteria for subject inclusion in the study population were: age between 18 and 45 years, having trained BJJ for a minimum of 6 months with the intensity of a minimum of 1.5 hours per week, having trained BJJ non-professionally (without participation in contests). The criteria for subject inclusion in the control group were: age between 18 and 45 years, being physically active except for training BJJ or any other sports professionally. The exclusion criteria for the study were: subjects below 18 years of age, with congenital disorders, chronic diseases or disability, as well as subjects with ongoing injuries or pain disorders in the locomotor system.

The subjects' age was between 24 and 43 years (in the study population it was $31.7 \pm 5.2$ years, and in the control group it was $29.7 \pm 4.36$ years). We did not find statistically significant differences between body mass or body height between the two groups. Table 1. presents the biometric data of the study population subjects. The mean time of training BJJ in the study population was $3.89 \pm 4.13$ years. The athletes trained a mean of $4.06 \pm 2.8$ times per week, and the training sessions were 1.5 hours long.

\section{Table 1. Subjects' biometric data}




\begin{tabular}{|c|c|c|c|c|c|c|c|c|}
\hline \multirow{3}{*}{$\begin{array}{l}\text { Descriptive statistics } \\
\text { Study population }(n=31)\end{array}$} & \multicolumn{2}{|c|}{ Age (years) } & \multicolumn{2}{|c|}{ Body mass (kg) } & \multicolumn{2}{|c|}{ Body height (cm) } & \multicolumn{2}{|c|}{ BMI (kg/m) } \\
\hline & & SD & & SD & & SD & & SD \\
\hline & 37.74 & 5.22 & 81.16 & 10.44 & 179.06 & 7.73 & 25.3 & 2.83 \\
\hline $\begin{array}{l}\text { Control group } \\
(n=30)\end{array}$ & 29.67 & 4.36 & 77.53 & 14.93 & 180.2 & 9.15 & 23.74 & 3.24 \\
\hline $\begin{array}{l}\text { Total } \\
(n=61)\end{array}$ & 30.72 & 4.89 & 79.38 & 12.87 & 179.62 & 8.41 & 24.53 & 3.11 \\
\hline Statistical significance $(p)$ & \multicolumn{2}{|c|}{$Z=1.52 p=0.126$} & \multicolumn{2}{|c|}{$Z=1.31 p=0.191$} & \multicolumn{2}{|c|}{$Z=-0.62 p=0.535$} & \multicolumn{2}{|c|}{$Z=2.19 p=0.029$} \\
\hline
\end{tabular}

Z-result of the U Mann-Whitney test; p-level of significance;

Postural stability assessment was conducted with the use of the photogrammetric method based on the projection of the moiré method. The equipment for the computer-based body posture assessment system Mora 4th Generation was used. This method is non-invasive, easy to use, easily available, and it is easy to analyse the obtained results. Moreover, the photogrammetric method allows for comparison of results, as it is increasingly often used in postural assessment studies. All the measurements were taken by the same researcher, a physiotherapist (K.S.), trained to operate the equipment while maintaining the constant conditions and procedure of the tests. Before the measurements were conducted a suitable room was adapted for the tests. The tests need to be conducted in a darkened room, so the windows were curtained, and the space in the room was organized properly so as to ensure safe and non-embarrassing conditions for conducting the measurements (the subjects needed to undress for the tests). To calibrate the Mora4G correctly, before each measurement session the device was adjusted using the spirit levels on the front and the side of the device. The researcher measured subjects' body mass and body height, and then, with the subject standing, marked palpated bony landmarks with a marker pen (spinous processes C7-S1, cervico-thoracic junction, thoracolumbar junction, scapula inferior angles, spina iliaca posterior superior, kyphosis peak, lordosis peak). To ensure comfortable and non-embarrassing conditions, female subjects could use a specially prepared cloth to cover the chest, attached to the body with adhesive tape. Subjects stood with their back to the projector-receiver device at a constant distance of $2.6 \mathrm{~m}$, with their feet placed under their hips and hands along the body, eyes looking forward. Then, the measurement was taken. According to the producer, the measurement error with the MORA 4G system is $1 \mathrm{~cm}$ at a maximum. Subjects' body posture was analysed in the sagittal, coronal and transversal planes, presented in Figure 1.

To analyse the photogrammetric measurements, we used the following parameters:

DCK (\%) Spinal height from C1 to S1

$\operatorname{ALFA}\left({ }^{\circ}\right) \quad$ Lumbosacral region inclination

$\operatorname{BETA}\left({ }^{\circ}\right) \quad$ Thoracolumbar region inclination

GAMMA $\left(^{\circ}\right)$ Upper thoracic region inclination

DKP ( $\mathrm{mm}$ ) The length of kyphosis between C7 and peak of kyphosis

KKP $\left(^{\circ}\right) \quad$ Thoracic kyphosis angle

RKP (mm) The length of kyphosis between $\mathrm{C} 7$ and thoracolumbar junction

GKP (mm) The depth of thoracic kyphosis 
DLL (mm) The length between S1 and peak of lordosis

$\mathrm{KLL}\left({ }^{\circ}\right) \quad$ Lumbar lordosis angle

RLL (mm) The length of lordosis between S1 and thoracolumbar junction

GLL (mm) The depth of lumbar lordosis

$\operatorname{KLB}\left({ }^{\circ}\right) \quad$ Shoulder line inclination difference

UB $\left(^{\circ}\right) \quad$ The difference in the depth of scapula inferior angles inclination

OL (\%) The difference between the distance of the scapula inferior angles from the spine

TT (\%) Difference in the height of the waist triangles

TS (\%) Difference in the width of the waist triangles

$\mathrm{KNM}\left({ }^{\circ}\right) \quad$ Angle of pelvis inclination

$\mathrm{KSM}\left({ }^{\circ}\right) \quad$ Angle of pelvis rotation

For the purpose of this study, the Polish validated version of the Oswestry Disability Index (ODI) was used. The ODI is used for the functional state assessment of patients with low back pain and it is the golden standard for the functional assessment in this group of patients. The questionnaire is accessible, patients can complete it on their own and it can be done in minutes. The subjects also filled out the author's original questionnaire consisting of 8 questions which comprised of the following: the biometric data (age, body mass, sex), data on the subjects' physical activity (duration, intensity, type), and injuries subjects sustained as well as spinal pain (location, symptoms, causes, pain intensity etc.).

\section{Statistical analysis}

Statistical analysis of the collected data was conducted with the STATISTICA 13 programme (TIBCO Software Inc., Palo Alto, CA, USA). Quantitative data was presented in the form of descriptive statistics using such measurements as arithmetic mean and standard deviation. The relationships between qualitative data were assessed with the chi-squared test, and the differences in two groups in quantitative data were assessed with the Mann-Whitney U-test. The non-parametric test was chosen as there was lack of normal distribution in the analysed variables. Normal distribution was verified with the ShapiroWilk test. Statistical significance was set at $p<0.05$.

\section{Results}

\section{Back pain and analysis of sustained injuries.}

Current back pain was present in 37 subjects (60.7\%), including $22(71.0 \%)$ athletes and $15(50.0 \%)$ controls $(p=0.094)$. The pain usually affected the lumbar spine (44.3\%), and it was less common in cervical spine (13.1\%) and thoracic spine $(18.0 \%)$. There were no differences in pain topography between the two groups, $p>0,05$. Pain intensity on the Numeric Rating Scale, NRS (from " 0 " meaning no pain to " 10 " meaning pain as bad as you can imagine) was $4.09 \pm 1.95$ points in the study population and $3.4 \pm 1.59$ point in the control group and it was statistically insignificant, $p=0,3$.

The subjects' disability was between minimal and moderate as shown by the ODI, and their results did not show statistically significant differences ( $21,5 \%$ for the studied population, $n=22 ; 20 \%$ for the control group, $n=15)$.

The most commonly reported injuries by study population subjects sustained because of BJJ training affected the knee (32.3\%), the auricle and the ankle (29.0\% each), and the elbow (16.1\%).

Page 5/11 
There were no statistically significant differences between the groups in physical activity $(\mathrm{p}=0.654)$. In the study population, 28 subjects (90.3\%) declared physical activity beside BJJ, with 26 subjects (86.7\%) in the control group. Training of other sports (beside BJJ) was done by subjects from both groups. BJJ athletes had other physical activity (beside BJJ) statistically significantly less often than the controls $(p=0.027)$. The study population did it a mean of $3,89 \pm 3,16$ times per week, and the control group $-5.73 \pm 3.47$ times per week. Other forms of physical activity of subjects from both groups included power workout (50.8\%), stretching (32.8\%), swimming (29.5\%), running (24.6\%) and cycling (19.7\%). Subject from control group went swimming statistically significantly more often than the study population subjects $(p=0.004)$.

\section{Body posture analysis}

We observed statistical differences between the two groups in the values of four of the studied parameters: DCK- spinal height, $p=0.001$, RKP- kyphosis height calculated between C7 and thoracolumbar junction, $p=0.010$, RLL- lordosis height calculated from S1 to the thoracolumbar junction, $p=0.009$ and KNM- angle of pelvis inclination, $p=0.041$. For each of these four parameters, the study population subjects had higher values than controls. Moreover, the BETA parameter thoracolumbar region angle and the TT parameter - difference in the height of the waist triangles had lower values in the study population. These values were close to the statistical significance, $p=0.063$ and $p=0.056$, respectively. Table 2 . presents studied parameters value.

Table 2. Photogrammetric measurement results in the study population and in the control group.

\begin{tabular}{|c|c|c|c|c|c|c|c|c|c|c|c|c|}
\hline \multirow[t]{2}{*}{$\begin{array}{l}\text { Analysed } \\
\text { parameters }\end{array}$} & \multicolumn{5}{|c|}{$\begin{array}{l}\text { Study population } \\
(\mathrm{n}=31)\end{array}$} & \multicolumn{5}{|c|}{$\begin{array}{l}\text { Control group } \\
(n=30)\end{array}$} & \multirow[t]{2}{*}{ Z } & \multirow[t]{2}{*}{$\begin{array}{l}\mathrm{p}- \\
\text { Value }\end{array}$} \\
\hline & & $\mathrm{Me}$ & Min. & Max. & SD & & $\mathrm{Me}$ & Min. & Max. & SD & & \\
\hline DCK [\%] & 474.8 & 473.5 & 412.1 & 520.8 & 25.4 & 447.1 & 448.0 & 402.7 & 499.1 & 25.9 & 3.73 & $0.001 *$ \\
\hline ALPHA $\left[^{\circ}\right]$ & 5.04 & 3.80 & 0.50 & 15.00 & 3.60 & 4.19 & 3.85 & 0.40 & 9.20 & 2.22 & 0.34 & 0.735 \\
\hline BETA $\left[^{\circ}\right]$ & 7.09 & 6.90 & 3.00 & 10.90 & 1.97 & 8.29 & 7.85 & 4.40 & 13.10 & 2.26 & -1.86 & 0.063 \\
\hline GAMMA $\left[^{\circ}\right]$ & 14.14 & 10.70 & 4.90 & 49.40 & 11.28 & 14.30 & 10.10 & 4.30 & 47.40 & 12.90 & 1.10 & 0.273 \\
\hline $\mathrm{DKP}[\mathrm{mm}]$ & 188.0 & 190.9 & 150.3 & 248.6 & 21.0 & 194.4 & 189.5 & 143.7 & 244.8 & 22.6 & -1.11 & 0.267 \\
\hline $\mathrm{KKP}\left[{ }^{\circ}\right]$ & 158.8 & 162.2 & 120.1 & 169.0 & 11.4 & 157.4 & 161.6 & 121.7 & 169.8 & 13.4 & 0.27 & 0.790 \\
\hline $\mathrm{RKP}[\mathrm{mm}]$ & 321.9 & 327.0 & 294.9 & 345.0 & 15.2 & 307.3 & 307.7 & 265.6 & 349.7 & 22.2 & 2.59 & 0.010 * \\
\hline $\mathrm{GKP}[\mathrm{mm}]$ & 16.58 & 16.60 & 1.50 & 27.80 & 6.58 & 16.43 & 15.45 & 3.80 & 36.90 & 5.85 & 0.02 & 0.983 \\
\hline DLL [mm] & 95.1 & 98.3 & 55.8 & 134.2 & 20.9 & 87.4 & 87.5 & 52.0 & 132.3 & 19.6 & 1.51 & 0.132 \\
\hline $\mathrm{KLL}\left[{ }^{\circ}\right]$ & 168.8 & 169.2 & 156.0 & 178.2 & 5.2 & 168.1 & 168.2 & 160.5 & 177.9 & 4.2 & 1.00 & 0.320 \\
\hline $\mathrm{RLL}[\mathrm{mm}]$ & 152.9 & 153.1 & 117.2 & 185.3 & 18.2 & 139.8 & 135.2 & 109.6 & 173.9 & 17.6 & 2.60 & $0.009 *$ \\
\hline GLL [mm] & 7.14 & 5.30 & 0.80 & 20.30 & 5.53 & 7.18 & 7.15 & 1.50 & 16.60 & 3.53 & -0.85 & 0.395 \\
\hline $\mathrm{KLB}\left[{ }^{\circ}\right]$ & 8.69 & 6.60 & 0.00 & 29.30 & 7.68 & 8.00 & 6.60 & 0.00 & 26.50 & 6.52 & 0.19 & 0.851 \\
\hline $\mathrm{UB}\left[^{\circ}\right]$ & 5.25 & 4.50 & 0.00 & 15.10 & 4.52 & 4.72 & 4.50 & 0.00 & 13.50 & 3.69 & 0.17 & 0.868 \\
\hline OL [\%] & 11.81 & 10.90 & 1.20 & 44.80 & 9.03 & 8.96 & 6.65 & 1.20 & 27.60 & 7.01 & 1.46 & 0.143 \\
\hline TT [\%] & 9.04 & 8.60 & 0.00 & 21.90 & 7.04 & 13.11 & 10.95 & 1.90 & 37.20 & 8.38 & -1.91 & 0.056 \\
\hline TS [\%] & 8.05 & 7.60 & 1.00 & 21.90 & 5.43 & 7.91 & 7.60 & 0.00 & 36.20 & 6.92 & 0.47 & 0.639 \\
\hline $\mathrm{KNM}\left[^{\circ}\right]$ & 2.24 & 2.40 & 0.00 & 4.20 & 1.18 & 1.64 & 1.30 & 0.00 & 4.80 & 1.34 & 2.05 & 0.041 * \\
\hline
\end{tabular}


Me-median; Min-minimum; Max-maximum; SD-standard deviation; Z-result of the Mann-Whitney U test; p-Value -level of significance of differences; * $-p<0.05$

We found statistically significant differences between subjects with and without back pain from the study population in the following parameters: RKP - the length of the thoracic kyphosis and TT- the differences in the height of the waist triangles. The RKP parameter values (athletes with pain $317.7 \pm 14.7$ vs. athletes without pain $332.2 \pm 11.7$ ) were statistically significantly lower in athletes with pain $(p=0.01)$. The TT parameter values (athletes with pain $10.88 \pm 7.06$ vs. athletes without pain $4,56 \pm 4,8)$ were statistically higher in athletes with pain $(\mathrm{p}=0.018)$. The mean training time in athletes with back pain was 3.5 years, and in athletes without back pain 4.7 years. There were no statistically significant differences in values of the studied parameters among the control group subjects with and without pain.

\section{Discussion}

Brazilian jiu-jitsu is becoming increasingly popular sport discipline. Several papers are being published on the injuries in BJJ, yet few studies focus on the long-term effect of its training, i.e. changes to the body posture, pain, and/or functional disorders in long-term cumulative effect of strains. There are some studies whose authors advise that it is necessary to conduct diagnostic tests to the reasons of LBP in athletes, $[14,15]$. They also mention that it is crucial to diagnose and eliminate LBP risk factors in order to facilitate LBP prevention [16]. The types of LBP causes in athletes include factors related to the requirements of a given sports discipline (sports such as gymnastics, diving, or volleyball require repeated hyperextensions [26]), a particular technique (e.g. twisting motion in the lumbar spine during backswing in golf [27]), strain and high training activity (the effort should be adjusted to athletes' physical abilities, and it is particularly important in young athletes to consider the developmental phase of the body and the growth spurt [16]), preparing athletes properly for training (developing and implementing LBP preventive programmes positively impacts lumbar motor control and posture[28]), history of past injuries (athletes who had sustained injuries to the back in the past are more susceptible to LBP [29],and injuries to the limbs may be related to LBP [30]). In recreational athletes, there are several additional risk factors related to life style (sedentary work, or physical load at work, shift work, lack of regular activity, unhealthy diet, distorted sleep patterns, distorted rest, high stress) [31].

In this study, both people training BJJ and people from the control group declared the occurrence of back pain. Pain frequency, location (in both groups it usually affected lumbar spine) and intensity were similar in both groups (between minimal and moderate on the ODI). It would be recommended for these subjects to receive suitable instructions on pain management in activities of daily life, i.e. on lifting objects, sitting or performing certain physical exercise correctly [32]. In the study by Reis et al. 35.6\% recreational athletes $(n=36)$ reported LBP, the results of the Quebec Back Pain Disability Scale (QBPDS) was low in both populations (professionals, Me:10; recreational, Me:6). Authors showed that professionals had a marginal increase in the risk factor of developing LBP in comparison to recreational sportsmen [19].

Sedentary lifestyle facilitates development of LBP. Although optimal dose of exercise and physical activity has not been determined [33], it seems justified to introduce modifications and adequate adaptation of BJJ training in recreational BJJ athletes with LBP. It seems important that subjects with back pain participate in training in the afternoon or evening instead of morning hours [10]. Moreover, athletes assume numerous position during training, particularly in numerous guards, and crossing the guard of the other contestant is an element of the bout [34]. These activities may generate loads for the spine because of alternating from maximal flexion to maximal extension. A recommendation for athletes with LBP may be using half-guard in training, so that the opponent does not lay his whole mass on the spine of the guard-keeping athlete. This would definitely reduce loads to the lumbar spine [10]. Sung-Jun Yang et al. [35] observed changes to hip rotation in BJJ athletes related to occurrence of LBP. This suggests the necessity for athlete assessment with regard to disorders and impairments of the locomotor system (movement range in the joints, muscle strength, movement system impairments) prior to training, or prior to those training elements which particularly load the lower spine. 
Studies on injuries in BJJ found that only $6 \%$ of injuries happen during contests [13] and that these are usually orthopaedic injuries [7] affecting mainly knees and elbows [8]. Most injuries happen during training [13] and they usually affect distal limb parts, i.e. hands, feet, fingers and toes [9]. Injuries which are reported to doctors or physical therapists usually affect lower extremities, while injuries to upper extremities, more commonly sustained during training, are probably not serious enough to require medical consultation $[9,12]$. Injuries to the back $(14.6 \%)$ are the third most common type of injury, after injuries to the lower extremities (38.1\%) and to the upper extremities (32.3\%). Here, the subjects usually reported injuries to the cervical spine [36]. In our study, the most commonly reported injuries sustained because of BJJ training by study population subjects affected the knee (32.3\%), the auricle and the ankle (29.0\% each), and the elbow (16.1\%). Injuries are more common in professional athletes and, as studies have shown, happen mainly in contests or during immediate preparation for contests. This may explain the smaller number of serious injuries in recreational athletes. The injuries they sustain are less serious than in professional athletes [12].

Our study has found changes to BJJ athletes' body postures in comparison to inactive subjects. These changes were found in four of the studied parameters (DCK, RKP, RLL and KNM). We found statistically significant differences between subjects with and without back pain from the study population in the following parameters: RKP and TT. BJJ athletes with LBP had shorter training time than BJJ athletes without LBT, which might suggest that BJJ has positive impact on body posture and LBP incidence. Similarly, to Walaszek et al. 2017 found that regular 6-month judo practice had positive effect on young judo athletes' body posture [37], and Grabara et al found that two years of volleyball training did not result in asymmetries in teenage athletes posture [22]. De Queiroz et al found improvement of functional fitness, health and quality of life in elderly men who trained BJJ for 12 weeks [38]. Postural disorders in athletes may result from the specificity of the sports discipline (repeated movements, asymmetric movements, wrong technique) [39], yet they may also be related to the past injuries. Regular recreational physical activity, e.g. BJJ may result in greater wellbeing and positive changes on body posture.

\section{Limitations}

The Mora system has numerous advantages, yet there is still certain risk of measurement error involved. We have tried to minimize the error in that all the measurements were conducted by the same researcher. Another limitation is that the intrarater correlation index has not been calculated. Unfortunately, no normative values are available for the Mora 4G that would allow us to refer the obtained results to them, and thus increase the value of the conducted analysis. Follow-up studies should include back pain diagnosis based on clinical examinations and possibly medical imaging. They should also focus on reasons why certain athletes have declined to participate in the study, or reason for absence of some athletes in training sessions (possibly related to back pain or an injury). This would allow for adjusting training and prevention for this sports discipline. As the study population was small we did not analyse the pain reported or postural differences separately for men and for women. The above-mentioned limitations do not decrease the value of this paper by any means. They may be treated as indications for further studies. Accepting these limitations, this article highlights differences in body postures in non-professional BJJ athletes in comparison to subjects who do not train this discipline. This is the first study to report postural changes in athletes reporting back pain in comparison to athletes without pain. This is also the first study to report how common lumbar spine pain is in recreational BJJ athletes.

\section{Conclusions}

1. There are no differences in back pain in regard to its frequency, intensity and location between non-professional BJJ athletes and subjects who do not train BJJ.

2. Both in the study population and in the control group the lower back pain was minimal or moderate on the Oswestry Disability Index.

3. BJJ athletes who reported back pain had characteristic postural changes in some of the analysed postural parameters in comparison to BJJ athletes who did not report back pain. 


\section{Declarations}

Ethics approval and consent to participate: The study were approved by the Senate Ethics Committee for Scientific Research (SKE 01-45/2016) and all participants gave their informed consent to participated in the project.

Consent for publication: All authors consent for the publication of data.

Data availability statement: Data available on request, contact with Anna Katarzyna Cygańska (anna.katarzyna.cyganska@gmail.com).

Competing interests: No conflict of interest.

Funding: This work was supported by the Ministry of Science and Higher Education in the year 2020 under Research Group no 4 at Józef Pilsudski University of Physical Education in Warsaw "Physical activity and sports for people with special need".

Authors' Contributions: KS: study design, data collection; literature search, manuscript preparation; AT-B: study design, have drafted the work and substantively revised it; AKC: literature search, statistical analysis; data interpretation, manuscript preparation and substantively revision; JD-G: have revised the manuscript; All authors read and approved the final manuscript.

Acknowledgements: Not applicable.

\section{References}

1. Andreato LV, Lara FJD, Andrade A, Branco BHM (2017) Physical and Physiological Profiles of Brazilian Jiu-Jitsu Athletes: a Systematic Review. Sport Med - Open. https://doi.org/10.1186/s40798-016-0069-5

2. Lima PO de P, Lima AA, Coelho ACS, Lima YL, Almeida GPL, Bezerra MA, de Oliveira RR (2017) BIOMECHANICAL DIFFERENCES IN BRAZILIAN JIU-JITSU ATHLETES: THE ROLE OF COMBAT STYLE. Int J Sports Phys Ther 12:67-74

3. Andreato L V., Julio UF, Gonçalves Panissa VL, Del Conti Esteves J V., Hardt F, Franzói De Moraes SM, Oliveira De Souza C, Franchini E (2015) Brazilian Jiu-Jitsu Simulated Competition Part II: Physical Performance, Time-Motion, TechnicalTactical Analyses, and Perceptual Responses. J Strength Cond Res 29:2015-2025

4. Andreato L V., Franchini E, De Moraes SMF, Pastório JJ, da Silva DF, Esteves JVDC, Branco BHM, Romero PV da S, Machado FA (2013) Physiological and technical-tactical analysis in brazilian jiu-jitsu competition. Asian J Sports Med 4:137-143

5. Spano M, Risucci D, Etienne M, Petersen K (2019) Epidemiology of Sports Related Concussion in Brazilian Jiu-Jitsu: A Cross-Sectional Study. Sports 7:53

6. das Graças D, Nakamura L, Barbosa FSS, Martinez PF, Reis FA, de Oliveira-Junior SA (2017) Could current factors be associated with retrospective sports injuries in Brazilian jiu-jitsu? A cross-sectional study. BMC Sports Sci Med Rehabil. https://doi.org/10.1186/s13102-017-0080-2

7. Scoggin JF, Brusovanik G, Izuka BH, van Rilland EZ, Geling O, Tokumura S (2014) Assessment of injuries during brazilian jiu-jitsu competition. Orthop J Sport Med. https://doi.org/10.1177/2325967114522184

8. Kreiswirth EM, Myer GD, Rauh MJ (2014) Incidence of injury among male brazilian jiujitsu fighters at the world jiu-jitsu No-Gi championship 2009. J Athl Train 49:89-94

9. McDonald AR, Murdock FA, McDonald JA, Wolf CJ (2017) Prevalence of Injuries during Brazilian Jiu-Jitsu Training. Sport (Basel, Switzerland) 5:39

10. Moriarty C, Charnoff J, Felix ER (2019) Injury rate and pattern among Brazilian jiu-jitsu practitioners: A survey study. Phys Ther Sport 39:107-113 
11. Jensen AR, Maciel RC, Petrigliano FA, Rodriguez JP, Brooks AG (2017) Injuries Sustained by the Mixed Martial Arts Athlete. Sports Health 9:64-69

12. Wisdom C, Valleser M (2017) Common Injuries of Recreational Jiu Jitsu. J Phys Educ Res 3:52-63

13. Petrisor BA, Del Fabbro G, Madden K, Khan M, Joslin J, Bhandari M (2019) Injury in Brazilian Jiu-Jitsu Training. Sports Health 11:432-439

14. Yamashita K, Sugiura K, Manabe H, Ishihama Y, Tezuka F, Takata Y, Sakai T, Maeda T, Sairyo K (2019) Accurate diagnosis of low back pain in adult elite athletes. J Med Investig 66:252-257

15. Sairyo K, Nagamachi A (2016) State-of-the-art management of low back pain in athletes: Instructional lecture. J Orthop Sci 21:263-272

16. De Luigi AJ (2014) Low back pain in the adolescent athlete. Phys Med Rehabil Clin N Am 25:763-788

17. Daniels JM, Pontius G, El-Amin S, Gabriel K (2011) Evaluation of low back pain in athletes. Sports Health 3:336-345

18. Trompeter K, Fett D, Platen P (2017) Prevalence of Back Pain in Sports: A Systematic Review of the Literature. Sport Med 47:1183-1207

19. Reis FJJ, Dias MD, Newlands F, Meziat-Filho N, Macedo AR (2015) Chronic low back pain and disability in Brazilian jiujitsu athletes. Phys Ther Sport 16:340-343

20. Özyürek S, Bayraktar D, Genç A (2018) Are the alterations in body posture related to decreased trunk muscle endurance in healthy young adults? J Back Musculoskelet Rehabil 31:431-436

21. Walaszek R, Sterkowicz S, Chwała W, Sterkowicz-Przybycień K, Walaszek K, Burdacki M, Kłys A (2017) Assessment of the impact of regular judo practice on body posture, balance, and lower limbs mechanical output in six-year-old boys. J Sports Med Phys Fitness 57:1579-1589

22. Grabara M (2020) Posture of adolescent volleyball players - a two-year study. Biomed Hum Kinet 12:204-211

23. Kruusamäe H, Maasalu K, Wyon M, Jürimäe T, Mäestu J, Mooses M, Jürimäe J (2015) Spinal posture in different DanceSport dance styles compared with track and field athletes. Med 51:307-311

24. Pereira RCM, Vigário PS, Mainenti MRM, Silva DTR, Lima TRL, Lemos T (2019) Computerized photogrammetric assessment of postural alignment in visually impaired athletes. J Bodyw Mov Ther 23:142-147

25. Williams JR (2008) The Declaration of Helsinki and public health. Bull World Health Organ 86:650-652

26. Bono CM (2004) Current Concepts Review: Low-Back Pain in Athletes. J Bone Jt Surg - Ser A 86:382-396

27. Vad VB, Bhat AL, Basrai D, Gebeh A, Aspergren DD, Andrews JR (2004) Low Back Pain in Professional Golfers: The Role of Associated Hip and Low Back Range-of-Motion Deficits. Am J Sports Med 32:494-497

28. Kiss G, Kovácsné VB, Tóth ÁL, Jeges S, Makai A, Szilagyi B, Ács P, Járomi M (2019) Efficiency examination of a 6-month trunk prevention program among recruitment kayak-canoe athletes: A randomized control trial. J Back Musculoskelet Rehabil 32:367-378

29. Greene HS, Cholewicki J, Galloway MT, Nguyen C V., Radebold A (2001) A history of low back injury is a risk factor for recurrent back injuries in varsity athletes. Am J Sports Med 29:795-800

30. Sekiguchi T, Hagiwara Y, Momma H, et al (2018) Youth baseball players with elbow and shoulder pain have both low back and knee pain: a cross-sectional study. Knee Surgery, Sport Traumatol Arthrosc 26:1927-1935

31. Björck-van Dijken C, Fjellman-Wiklund A, Hildingsson C (2008) Low back pain, lifestyle factors and physical activity: A population-based study. J Rehabil Med 40:864-869

32. Miekisiak G, Kollataj M, Dobrogowski J, et al (2013) Validation and cross-cultural adaptation of the polish version of the oswestry disability index. Spine (Phila Pa 1976). https://doi.org/10.1097/BRS.0b013e31827e948b

33. Heneweer H, Staes F, Aufdemkampe G, Van Rijn M, Vanhees L (2011) Physical activity and low back pain: A systematic review of recent literature. Eur Spine J 20:826-845

Page $10 / 11$ 
34. Lima PO de P, Lima AA, Coelho ACS, Lima YL, Almeida GPL, Bezerra MA, de Oliveira RR (2017) BIOMECHANICAL DIFFERENCES IN BRAZILIAN JIU-JITSU ATHLETES: THE ROLE OF COMBAT STYLE. Int J Sports Phys Ther 12:67-74

35. Sung-jun Yang; Kyue-nam Park; Moon-soo Kyung; Si-hyun Kim (2018) Comparison of Hip Rotation Range of Motion in Jiu-Jitsu Athletes with and Without Low Back Pain. 25:47-52

36. Moriarty C, Charnoff J, Felix ER (2019) Injury rate and pattern among Brazilian jiu-jitsu practitioners: A survey study. Phys Ther Sport 39:107-113

37. Walaszek R, Sterkowicz S, Chwała W, Sterkowicz-Przybycień K, Walaszek K, Burdacki M, Kłys A (2017) Assessment of the impact of regular judo practice on body posture, balance, and lower limbs mechanical output in six-year-old boys. $J$ Sports Med Phys Fitness 57:1579-1589

38. de Queiroz JL, Sales MM, Sousa CV, da Silva Aguiar S, Asano RY, de Moraes JFVN, Soares BRA, Neves RVP, de Moraes MR, Simões HG (2016) 12 weeks of Brazilian jiu-jitsu training improves functional fitness in elderly men. Sport Sci Health 12:291-295

39. (2016) POSTAWA CIAŁA ZAWODNIKA KLASY MISTRZOWSKIEJ W JU-JITSU, STUDIUM PRZYPADKU. Kult Bezpieczeństwa Nauk 61-80

\section{Figures}
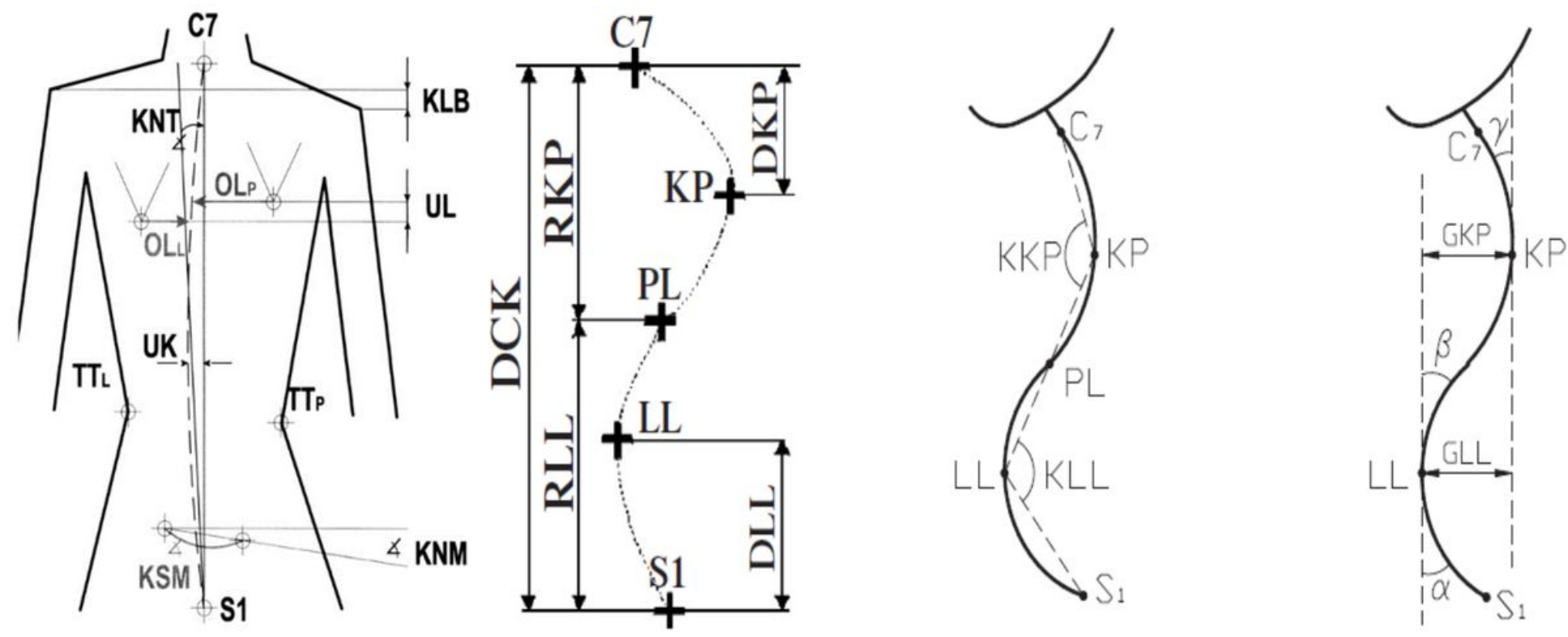

Figure 1

Analysed parameters in the coronal and sagittal plane. Source: http://www.cq.com.pl [04.09.2020 r.] 